\title{
Where is my ear? - Cervical Chondrocutaneous Branchial Remnant
}

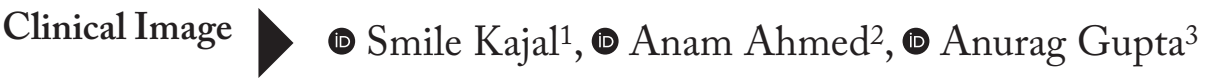 \\ ${ }^{1}$ Department of Otorhiolaryngology and Head-Neck Surgery, All India Institute of Medical Sciences, Delhi, India \\ ${ }^{2}$ Department of Anatomy, All India Institute of Medical Sciences, Delhi, India \\ ${ }^{3}$ Department of Pathology, University College of Medical Sciences, Delhi, India
}

ORCID ID of the authors:

S.K. 0000-0002-1364-7028; A.A. 0000-0002-7051-3990; A.G. 0000-0003-3776-3143.

Cite this article as: Kajal S, Ahmed A, Gupta A. Where is my ear? - Cervical Chondrocutaneous Branchial Remnant. Turk Arch Otorhinolaryngol 2021; 59(3): 242-3.

Corresponding Author: Smile Kajal; smilekaja192@yahoo.com

Received Date: 19.07.2021 Accepted Date: 29.08.2021

Content of this journal is licensed under a Creative Commons Attribution 4.0 International License. Available online at www.turkarchotolaryngol.net (c) (i) \$

DOl: 10.4274/tao.2021.2021-6-13
A 6-year-old boy presented with the absence of pinna on the left side since birth. A cutaneous appendage emerging from the neck on the left side was discovered during the examination (Figure 1). Deep palpation revealed a firm texture like cartilage. On the left side, a primitive firm cartilage was palpated in the helix region (Figure 2). The rest of the cartilaginous framework and external auditory canal (EAC) opening was absent on the left side. On the right side, the pinna was smaller in size and loped. High resolution computed tomography (HRCT) of temporal bone showed an atretic and stenosed EAC on the left and ride side, respectively. Ossicular lump was noted on both sides on HRCT, but all inner ear structures appeared normal in both ears. Pure tone audiometry revealed moderate and mild conductive hearing loss on the left and right sides, respectively. Magnetic resonance imaging of the neck was done to rule out any branchial abnormality. It did not reveal any cyst/sinus/fistula. A provisional diagnosis of cervical chondrocutaneous branchial remnant (CCBR) with left- sided microtia and EAC atresia was made on clinico-radiological basis. After a thorough discussion with the father, the patient was planned for the excision of the cervical mass and staged pinnaplasty and canaloplasty on the left side at a later stage. Histopathological examination after excision showed elastic cartilage rests covered by normal skin consisting of epidermis, dermis, adnexal structures, and subcutaneous fat compatible with CCBR.

The development of six cartilaginous tubercles known as "Hillocks of His" initiates the development of pinna in the sixth week of pregnancy. The first three hillocks are formed by the first branchial arch, while the remaining three are formed by the second branchial arch (1). The lobule is the first external ear component to develop. The growing pinna is first found in the neck, but by the 20th week of pregnancy, it has ascended to its usual adult location and structure (2).

An accessory tragus is formed from the first branchial arch and is usually found along an imaginary line drawn from the tragus to the angle of the mouth, whereas CCBR 


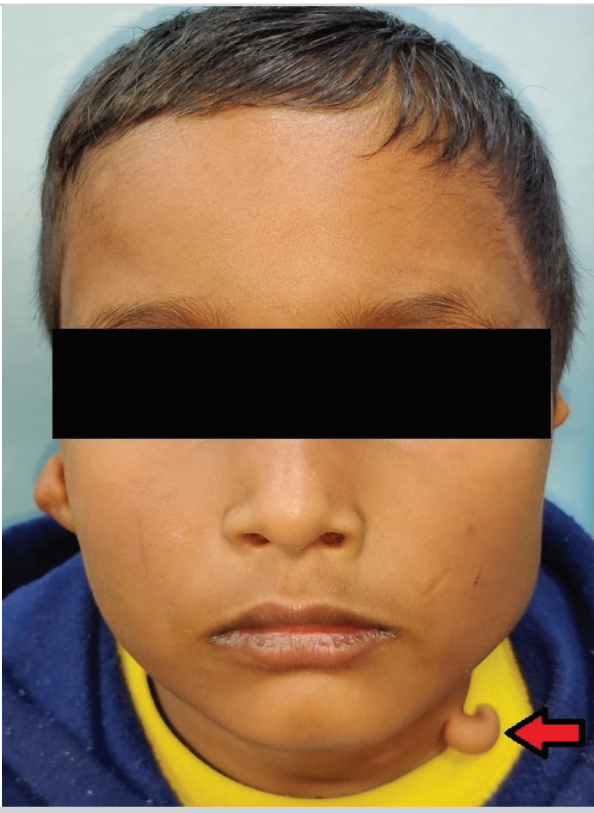

Figure 1. Frontal view showing cervical chondrocutaneous branchial remnant arising from neck on the left side (red arrow)

is derived from the second branchial arch and is found over the lower one-third of the sternocleidomastoid (SCM) (3, 4). However, they may be of auricular origin (due to failure of migration and contain elastic cartilage) or may represent primordial laryngeal remnants of the second and third branchial arches containing hyaline cartilage. They present as painless neck masses resembling skin tags anterior to SCM, with no overlying skin changes and more common in males. Imaging of the neck is done to see the extent of the lesion and to rule out other branchial abnormalities. CCBRs usually do not involve underlying neck structures. However, they may be associated with other congenital malformations involving the genitourinary tract and may warrant ultrasound screening of the kidney and urinary tract. In our case, the patient did not have any other systemic symptoms and his abdominal, renal, and urinary system ultrasound scanning was normal. The differential diagnosis may include fibroepithelial polyp, epidermoid cyst, and squamous papilloma. The treatment is usually surgical excision until the superficial muscular plane. Recurrence and malignant transformation have not been reported in the literature $(4,5)$.

Informed Consent: Informed consent form was obtained from the patient's parents.

Peer-review: Externally peer-reviewed.

Conflict of Interest: No conflict of interest was declared by the authors.

Financial Disclosure: The authors declared that this study received no financial support.

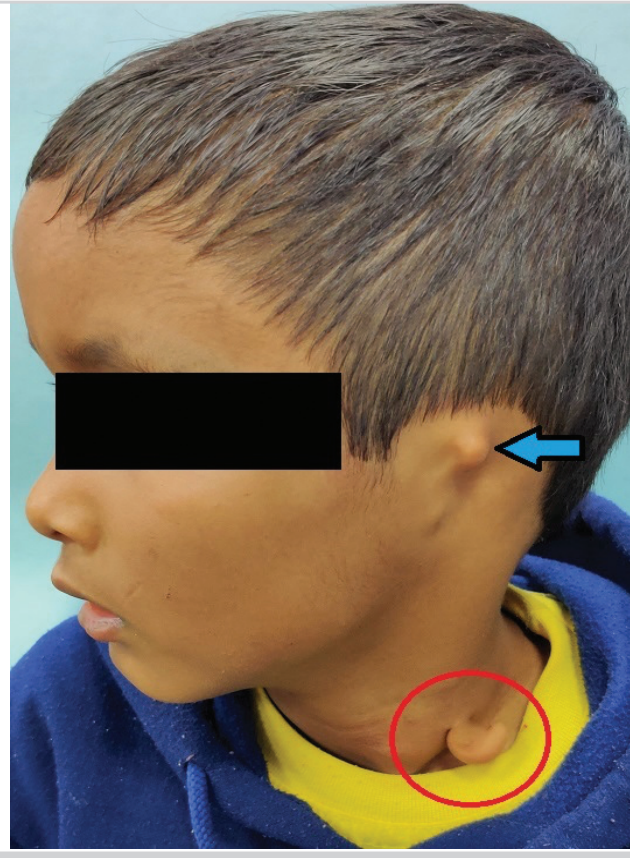

Figure 2. Lateral view showing cervical chondrocutaneous branchial remnant (red circle) and a rudimentary cartilaginous structure (accessory tragus?) buried under the skin in region of helix on the left side (blue arrow)

\section{Authorship Contributions}

Concept: S.K., Design: S.K., Data Collection and/or Processing: A.A., A.G., Analysis and/or Interpretation: S.K., A.A., A.G., Literature Search: S.K., A.A., A.G., Writing: S.K., A.A.

\section{Main Points}

- Pinna develops from six cartilaginous tubercles known as "Hillocks of His".

- Cervical chondrocutaneous branchial remnant usually forms due to defect in migration of these tubercles during embryonic development and can be confused with accessory tragus.

- Treatment is surgical excision till superficial muscular plane.

\section{References}

1. Anthwal N, Thompson $\mathrm{H}$. The development of the mammalian outer and middle ear. J Anat 2016; 228: 217-32. [Crossref]

2. Armin BB, Ruder RO, Azizadeh B. Partial auricular reconstruction. Semin Plast Surg. 2011; 25: 249-56. [Crossref]

3. Khandelwal V, Banda NR, Nayak UA, Banda VR. Accessory tragus: a dentist's perspective. BMJ Case Rep 2013; 2013: bcr2013008645. [Crossref]

4. Nielsen LJ, Von Rosen K, Jakobsen LP. Cervical chondrocutaneous branchial remnants: a case report. Eplasty 2016; 16: ic17. [Crossref]

5. Ibrahim S, Byrd C, Kubek D. Cervical chrondrocutaneous branchial remnant: A case report. Otolaryngol Case Reports 2020; 17: 100241. [Crossref] 